\title{
TWO-DIMENSIONAL FEM-ANALYSIS OF EDDY CURRENTS LOSS IN LAMINATED MAGNETIC CIRCUITS
}

\begin{abstract}
Purpose. One of the solutions of the problem of taking into account losses in laminated magnetic circuits caused by eddy currents was examined. The proposed solution is intended for use in specialized mathematical models, which are based on a twodimensional description of the electromagnetic field. The algorithm for calculating the equivalent value of the specific electrical resistance of the material of the magnetic circuit is based on the FEM analysis of the spatial distribution of the current density vector in the laminated magnetic core model, as well as the magnetic and electrical properties which are as close as possible to electrotechnical steel. The principal possibility of using the proposed approach was confirmed by comparing the calculated and experimental time dependences of the regime values, for example, of a single-phase transformer operating at different voltage supply frequencies. References 11, tables 3, figures 6.
\end{abstract}

Key words: eddy current losses, laminated magnetic core, two-dimensional FEM analysis, single-phase transformer.

Розглядається одне з вирішень проблеми врахування втрат потужнності в шихтованих магнітопроводах, щио викликані вихровими струмами. Запропоноване рішення призначене для використання у спеціалізованих математичних моделях, які трунтуються на двовимірному описі електромагнітного поля. Алгоритм розрахунку еквівалентного значення питомого електричного опору матеріалу магнітопроводу побудовано на підставі FЕМ-аналізу просторового розподілу вектора густини струму в иихтованому взірці, магнітні та електричні властивості якого максимально наближені до електротехнічної сталі. Принципова можливість використання пропонованого підходу підтверджусться порівнянням розрахункових та експериментальних часових залежностей режимних величин, на прикладі однофазного трансформатора, щцо працює за різних частот напруги живлення. Бібл. 11, табл. 3, рис. 6.

Ключові слова: втрати від вихрових струмів, шихтований магнітопровід, двовимірний ҒЕМ- аналіз, однофазний трансформатор.

Introduction. Despite the fact that the methods of calculating the field of the vector of current density in electrically conductive areas of arbitrary configuration are well known, mathematical models that are intended for analysis of energy conversion processes in objects with laminated magnetic cores are usually based on assumptions about the absence of losses from them. There are several reasons for this discrepancy between the theoretical level and the practical implementation of the algorithms of mathematical models of electromechanical energy converters, in particular, the need for an extremely high level of discretization of the calculated area. Also, the directions of vectors of current density and vector magnetic potential do not always coincide in the modes close to saturation.

Both of these factors lead to the need to use powerful computing technology, which is far from always guaranteeing the creation of mathematical models with desirable performance indicators - fast performance, acceptable RAM and precision.

The analysis of recent research. The relevance of this issue is evidenced by numerous publications.

The approaches described in [1-3] are based on the results of the calculation of the magnetic field obtained by a specific conversion of the characteristics of the magnetization of materials, and are intended for further determination of losses in the steel.

The authors apply the principle of overlay in relation to the non-linear system.

Attempts for analytical calculation of losses in laminated areas of simple form are described in [4, 5]. In 3 the importance of taking into account the distribution of the current density field at least in several outer sheets of the laminated packet is emphasized.

In 5 the mutual influence of hysteresis losses and eddy current losses is investigated. It is pointed out that this effect is fairly significant, but unfortunately, the question of creating adequate models for its inclusion in dynamic regimes is not considered. Similarly, in 6, solving the problem in terms of the magnetic scalar potential, the authors propose a method for replacing a laminated medium so that an adequate reflection of the magnetic field is achieved in the problems of magnetostatics. The issue of determining the losses in these materials remains open.

This problem is solved, but in a three-dimensional space in 7. For field problems, it is proposed to use homogeneous materials, anisotropic in both electrical and magnetic terms.

The authors of the paper 8 are engaged in the study of the dependences of specific losses in the laminated cores, depending on the field intensity and in the wide frequency domain $(20 \div 2000 \mathrm{~Hz})$. The influence of the interaction of these factors is shown. The paper contains interesting experimental material.

In terms of the classical theory of circles, the problem of taking into account losses in the material, which considers both hysteresis and eddy currents, is solved in 9. Non-linear properties of the material are specified using additional elements of the sub-scheme.

The publication 10 directly addresses the issues outlined above. For relatively geometrically simple forms of magnetic conductors, it is proposed to apply the original numerical calculation algorithm for surface integrals that the finite element method (FEM) operates. Thus, the field of the densities of currents for equivalent homogeneous structures, deprived of air gaps, is determined. The method is quite attractive, but the plane of the calculation area should be located perpendicular to the main magnetic flux. In the most tasks of

(C) Makarchuk O., Całus D., Moroz V., Gałuszkiewicz Z., Gałuszkiewicz P. 
electromechanics of practical interest, this plane should be oriented parallel to the direction of flux.

Formulation of the problem. It is clear that in the transition from a real three-dimensional to twodimensional description of the quantities describing the spatial distribution of losses in laminated electric conductive cells, the picture of physical phenomena varies on a qualitative level. Replacing the laminated magnetic core with a homogeneous medium, in a two-dimensional approximation, changes the real direction of the current density vector to one that is perpendicular to the surface of the calculated domain. The phenomena associated with the dumping of the magnetic flux by the «current layer» are to some extent distorted.

The logical question arises whether it is possible to replace the laminated magnetic core with a homogeneous medium with some calculated values of the specific electrical resistance, so that for a two-dimensional magnetic field approximation, the loss from eddy currents in this medium is equal to the losses in the volume of the real magnetic core? How to determine the value of this equivalent specific resistance?

The purpose of the study. An analysis of the fundamental possibility of creating mathematical models of EMPE, which, in the two-dimensional approximation of a quasi-steady-state magnetic field, will adequately consider the losses from eddy currents in the laminated elements of the magnetic conductors in both the established and transient operating modes.

The subject of study. The processes are related to the spatial distribution of the vector of current density and power losses in laminated magnetic cores of electric machines and apparatuses.

Methods. To achieve the goal, two mathematical models have been created. They both have the same purpose: the calculation of the fields of current density and losses in the conductive model, located in the time variable magnetic field.

The sample is a parallelepiped loaded with sheets of electrotechnical steel of rectangular shape. The sheets are separated from each other by air spaces. In the future, we will call it «model of type $3 D »$ or $« 3 D »$.

In it, the sample is a rectangular plane of a homogeneous material, which corresponds to the size and magnetic properties of a sheet from a three-dimensional model, and its specific electrical resistance is calculated. Let's call it «model of type $2 D »$ or « $2 D »$.

All dimensions, fill factor and electrical resistance of samples' material can vary widely. Also, the models parameters are the magnetization characteristic of the material as a table-defined function.

The mathematical formulation of these tasks is based on Maxwell equations and uses the Coulomb gauge. In invariant notation, it is reduced to the expression

$$
\nabla^{2} \bar{A}=\sigma \nabla U+\sigma \frac{\partial \bar{A}}{\partial t},
$$

where $\nabla$ is a differential operator of Hamilton; $\bar{A}$ is a vector magnetic potential; $U$ is a scalar electric potential; $\sigma$ is the specific electrical conductivity of the medium.

The field of the vector of current density is determined by the formula

$$
\bar{J}=\sigma\left(-\nabla U-\sigma \frac{\partial \bar{A}}{\partial t}\right) .
$$

The solution (1), (2) provided using the finite element method using the specialized software Ansys. After that, the power losses in the volume of the conductive area are found as

$$
P_{c r}=\sigma^{-1} \int_{V}|\bar{J}|^{2} d V=\sigma^{-1} \sum_{e=1}^{E}\left(\frac{V^{[e]}}{K} \sum_{k=1}^{K}\left|J_{k}\right|^{2}\right),
$$

where $d V$ is the volume of the elementary domain; $J_{k}$ is a module of the node value of the current density vector; $k=\overline{1, K}$ is a current node number of the finite element; $e=\overline{1, E}$ is a current finite element number, which belongs to conductor volume $V ; V^{[e]}$ is the volume of $e$-th finite element.

For a two-dimensional case in (3), $V$ should be replaced with $S l$ and $V^{[e]}$ with $S^{[e]} l$, where $S, S^{[e]}$ is the area of the calculated domain and finite element domain respectively; $l$ is the length of the calculated area in the direction $z$ coordinates.

In a three-dimensional model, there exists a number of planes, for which the field of vector potential is symmetric. Using this property, the calculated area occupies only $1 / 4$ of the volume of the complete model, which allows to reduce the dimension of the problem by 4 times. The view of the calculated area and its binding to the coordinate system is shown in Fig. 1,a.
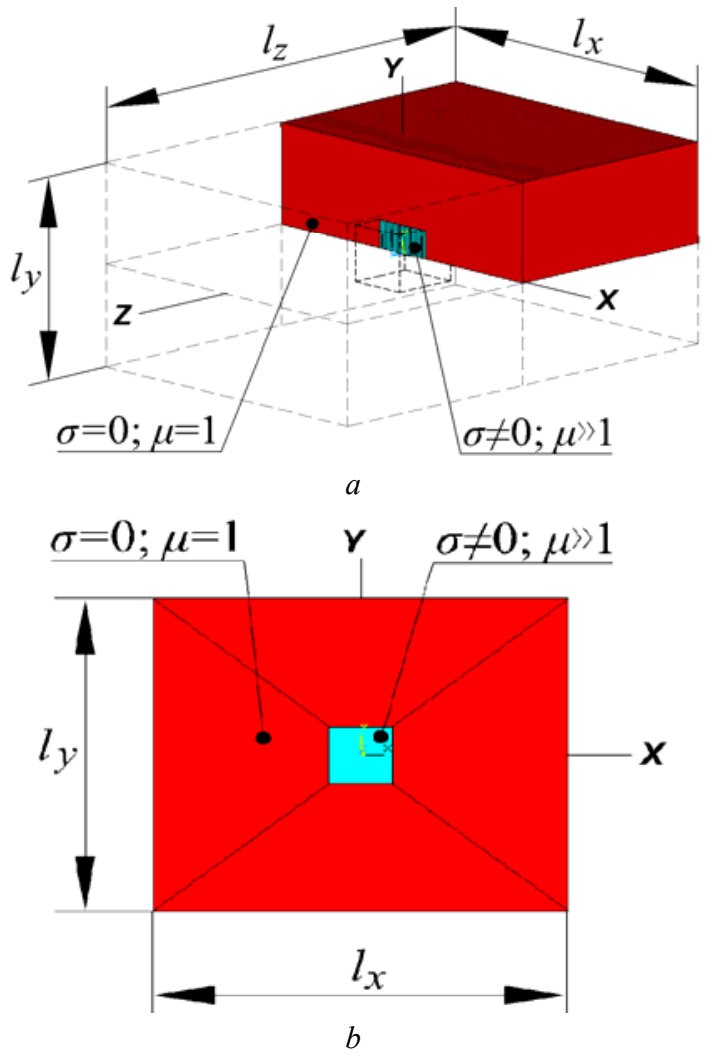

Fig. 1. Calculated areas of models: 3D (a); 2D (b)

The boundary condition and symmetry condition for this problem are summarized in Table 1. The level of discretization of the volume of the calculated area is schematically shown in Fig. 2, $a$. 
Table 1

The boundary conditions and symmetry conditions

\begin{tabular}{|c|c|}
\hline \multicolumn{2}{|c|}{ Dimension of the problem $-3 D$} \\
\hline Plane equation & Boundary condition \\
\hline$x=-0.5 l_{x} ; x=0.5 l_{x}$ & $A_{x i}=\frac{2 z_{i}}{l_{z}} A_{m} \sin (\omega t) ; A_{y i}=0 ; A_{z i}=0$ \\
\hline$y=0.5 l_{y}$ & $A_{x i}=\frac{2 z_{i}}{l_{z}} A_{m} \sin (\omega t) ; A_{y i}=0 ; A_{z i}=0$ \\
\hline$z=-0.5 l_{z}$ & $A_{x i}=-A_{m} \sin (\omega t) ; A_{y i}=0 ; A_{z i}=0$ \\
\hline Plane equation & Symmetry condition \\
\hline$z=0$ & $A_{x i}=0, A_{y i}=0($ condition of parallel flow $) ;$ \\
\hline$z=0$ and $\sigma \neq 0$ & $U=0$ \\
\hline$y=0$ & $A_{v i}=0($ condition of perpendicular flow $)$ \\
\hline \multicolumn{2}{|c|}{ Dimension of the problem $-2 D$} \\
\hline Equation of line & Boundary condition \\
\hline$x=-0.5 l_{x} ; x=0.5 l_{x}$ & $A_{z i}= \pm A_{m} \sin (\omega t)$ \\
\hline$y=-0.5 l_{y} ; y=0.5 l_{y}$ & $A_{z i}=\frac{-2 x_{i}}{l_{x}} A_{m} \sin (\omega t)$ \\
\hline
\end{tabular}

Marks: $A_{x i}, A_{y i}, A_{z i}$ are the values of the projections of the vector of the magnetic potential in the $i$-th node; $A_{m}$ is the amplitude of vector magnetic potential; $x_{i}, z_{i}$ are coordinates of $x$ or $z$ for $i$-th node.
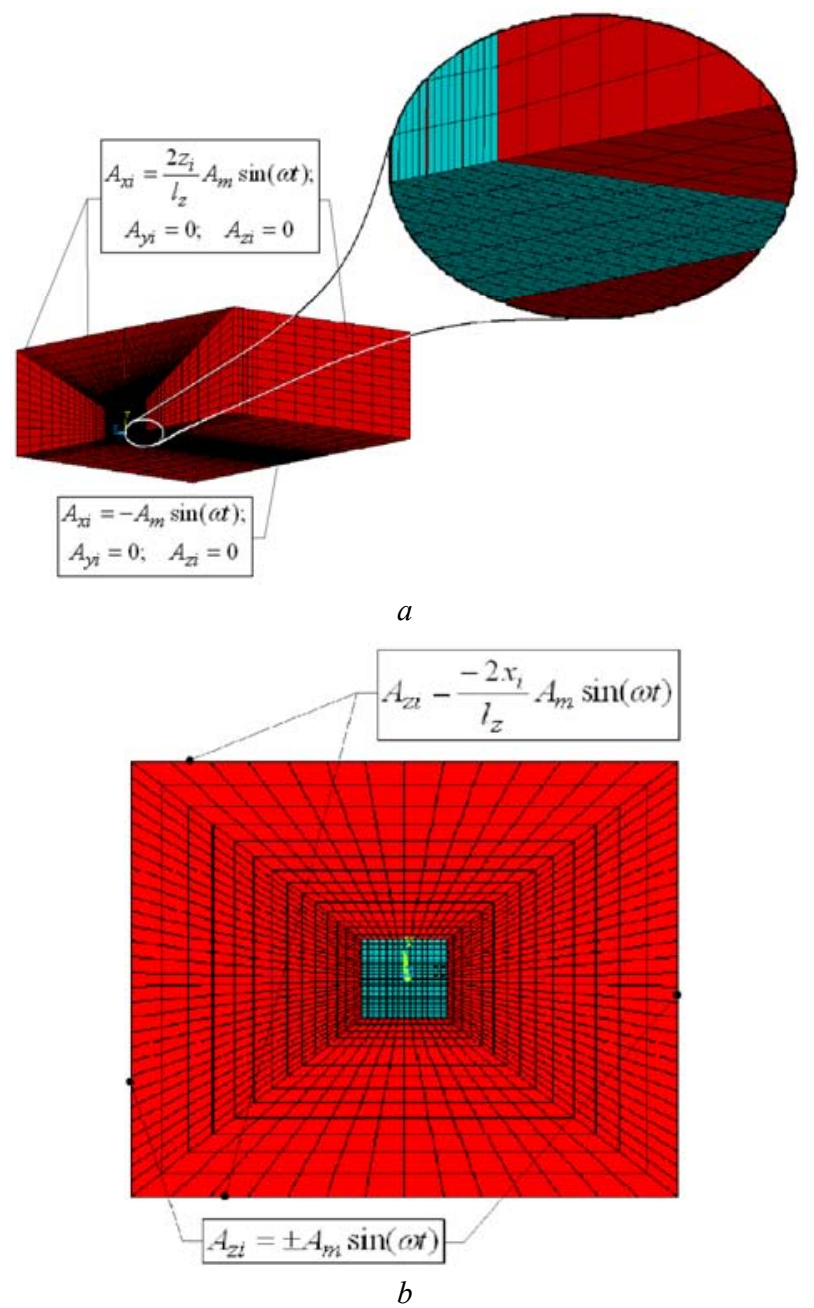

Fig. 2. Finite elemental models: 3D (a); 2D (b)

For a two-dimensional model of binding to the coordinate system is shown in Fig. 1,b, the boundary condition is shown in Table 1 , the level of sampling is given in Fig. 2, $b$.
By processing the results of numerical simulation, which changed the dimensions of the electrotechnical steel 2013 sample $(3 \div 20 \mathrm{~mm}$, the thickness of the sheet is $0.35 \div 1.0 \mathrm{~mm})$, the material resistivity $(0.14 \div 0.50 \mu \Omega \cdot \mathrm{m})$ and the intensity of the magnetic field $(0.7 \div 2.0 \mathrm{~T})$, the empirical dependence has been obtained which allows determining the equivalent resistivity of the magnetic core material, depending on the ratio of dimensions

$$
\rho_{e}=\frac{1}{\sigma_{e}}=k_{f}\left(\frac{l}{t}\right)^{2} \rho_{m},
$$

where $\rho_{m}$ is the specific electrical resistivity of the material of the magnetic core (according to reference data, for example GOST 21427.2-83), $l$ is the size of the area of the magnetic core in the direction perpendicular to the direction of passage of the main magnetic flux (for the toothed areas - the average width of the teeth, for a jar of electric machines - the thickness of the yoke in the radial direction); $t$ is thickness of the sheet of the laminated core; $k_{f}$ is a coefficient of the form of the core (correction coefficient). If the ratio of sizes $l / t$ belongs to the range $3 \div 20$, we suggest that its value be calculated according to the formula

$$
k_{f}=4.02-0.276\left(\frac{l}{t}\right)+0.0044\left(\frac{l}{t}\right)^{2} .
$$

and if exceeds 20 - choose from Table 2.

It is (4) that we propose to use to account for the losses in laminated magnetic circuits in field $2 D$ models.

Table 2

The value of the form factor

\begin{tabular}{|c|c|c|c|c|}
\hline$l / t$ & 5 & 10 & 20 & $>40$ \\
\hline$k_{f}$ & 2.75 & 1.7 & 0.27 & 0.075 \\
\hline
\end{tabular}

Results and discussion. For a laminated test component of $10 \times 10 \times 10 \mathrm{~mm}$ with a sheet thickness of $0.5 \mathrm{~mm}$, a material fill factor of 0.95 , with magnetic properties corresponding to the electrotechnical steel 2013 and a specific electrical resistance of $0.14 \mu \Omega \cdot m$, using the $3 D$ type model, dependences on the specific power losses $\left[\mathrm{W} / \mathrm{m}^{3}\right]$ from the active value flux density, averaged over the volume of the whole model (Fig. 3) were obtained. Similar dependencies are obtained on the model $2 D$, but the resistivity of the material, in this case, is increased by 109 times, to a value of $15.26 \mu \Omega \cdot \mathrm{m}$.

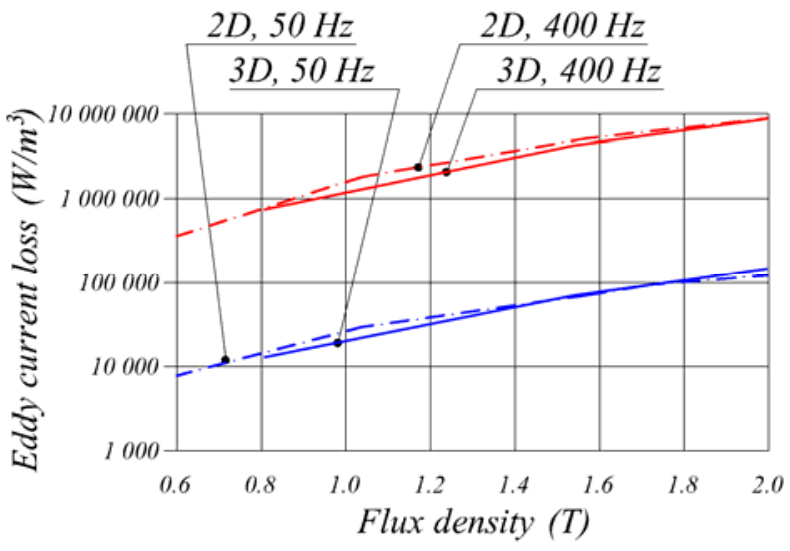

Fig. 3. Dependences of specific losses in the laminated model from flux density 
The comparison of these dependencies, for the frequency changes of the 50 and $400 \mathrm{~Hz}$ field, shows a good convergence of results. This comparison and analysis of the results of mathematical experiments carried out using the above-mentioned models $3 D$ and $2 D$ allow to declare the following:

- known methods for calculating the losses in the laminated cores, for example, according to the Krug formula, in conditions close to the saturation of the material make a significant error both at the industrial and higher frequencies of field change;

- two-dimensional approximation of the magnetic field allows considering the effect of eddy currents in the laminated cores by converting the value of the resistivity of the material.

Fig. 4 shows the distribution of instantaneous values of the module of the current density vector in a threedimensional laminated model (Fig. 4,a) and a twodimensional model (Fig. 4,b), where the resistivity of the material is determined by (4). As can be seen from Fig. 4, the distribution of the vector of current density in $2 D$ and $3 D$ cases varies, but the average for the period of power loss in the two samples is practically same, as illustrated in Fig. Note, that the negative value in Fig. 4,b corresponds to the direction $z$-projections of the current density vectors, directed from the observer.
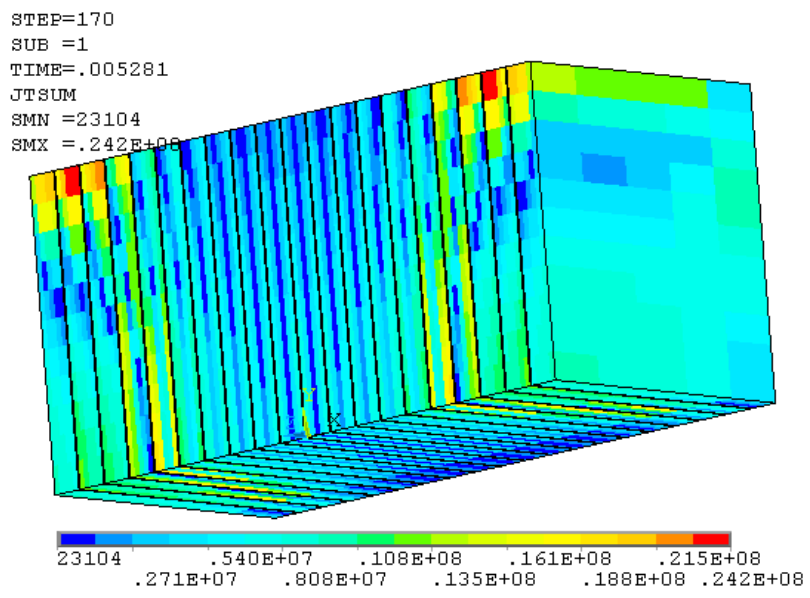

$a$

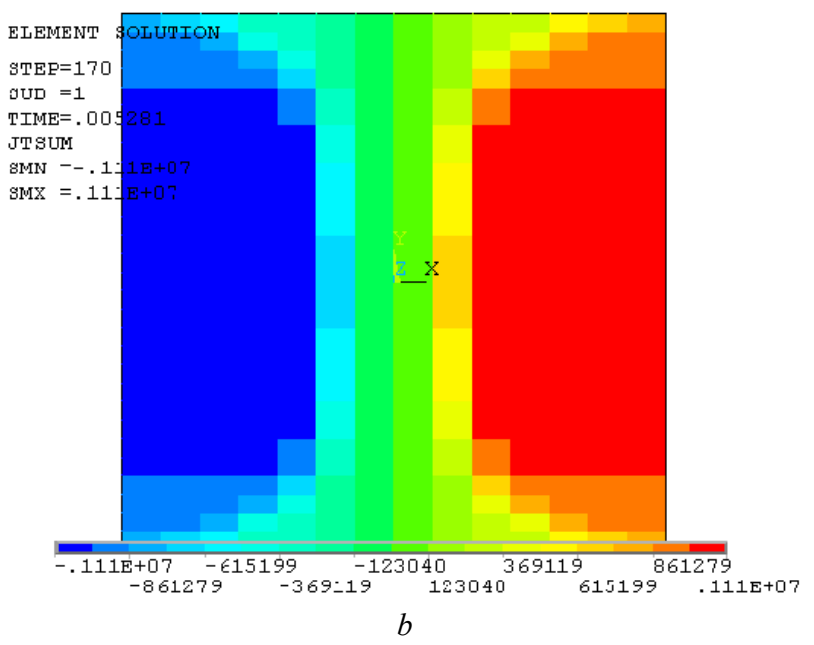

Fig. 4. Current density vector field $(t=5.281 \mathrm{~ms}, f=400 \mathrm{~Hz})$ : $3 \mathrm{D}(a) ; 2 \mathrm{D}(b)$
To verify the correctness of the accepted assumptions, a physical experiment has been performed to record the instantaneous steady-state values of current and voltage in the primary winding of a single-phase transformer in idle mode. The experiment has been conducted for two frequencies of supply voltages. For a frequency of $50 \mathrm{~Hz}$, the current voltage of $150 \mathrm{~V}$ is applied to a winding that had 609 turns. The active resistance of this winding is $18.3 \mathrm{Ohms}$. For a frequency of $495 \mathrm{~Hz}$, the value of the voltage is $40 \mathrm{~V}$, the number of turns of the winding is 170 and its resistance is 0.585 Ohms. Overall dimensions of the core of the investigated transformer are $94 \times 81 \times 26.7 \mathrm{~mm}$ (Fig. 5), and its magnetic properties correspond to the electrotechnical steel 2411.

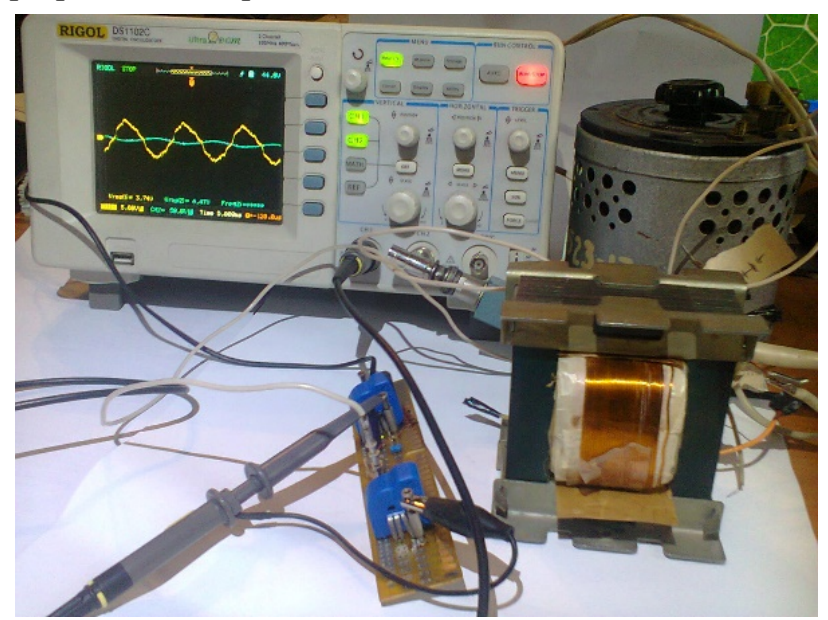

Fig. 5. Investigated transformer and measuring equipment

The results of the experiment are compared with the calculated values of the non-operating current, obtained on a specially created mathematical model of the aforementioned transformer. This model calculates the two-dimensional approximation of the magnetic field constructed based on approach (1) and uses the core material with magnetic properties of 2411 and equivalent to the specific electrical resistance of $190.8 \mu \Omega \cdot \mathrm{m}$, obtained on the basis of (4) and with subsequent correction of its value.

The results of this comparison are shown in Fig. 6. It also depicts the calculated current dependencies in windings from time to time, provided that there are no eddy currents in the core $(\sigma=0)$.

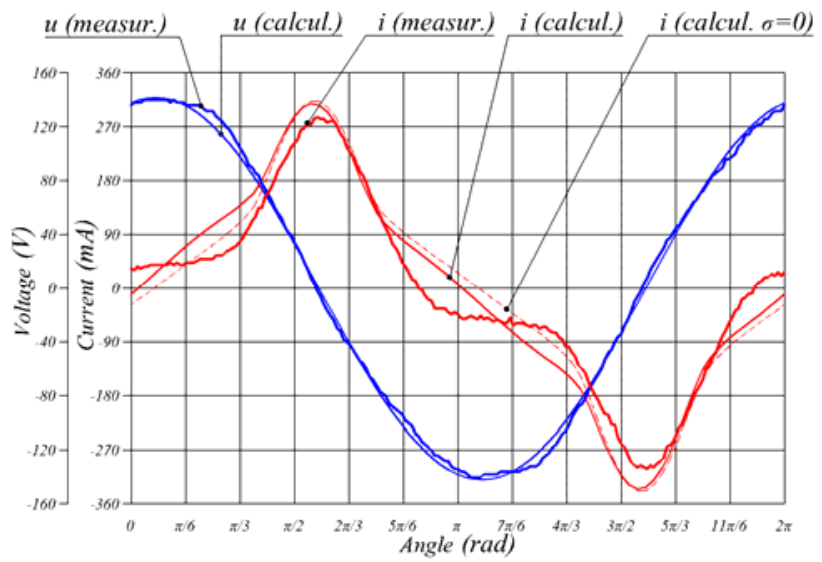

$a$ 


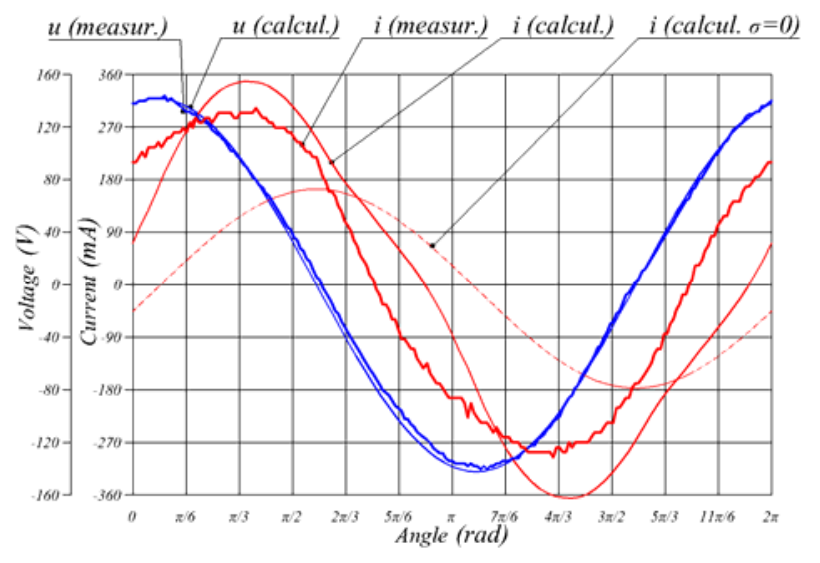

b

Fig. 6. Dependences of currents and voltages of the transformer on: $50 \mathrm{~Hz}(a) ; 495 \mathrm{~Hz}(b)$

The comparison of average values of power consumed in these regimes is summarized in Table 3.

Table 3

Comparison of average values of power consumption

\begin{tabular}{|c|c|c|c|}
\hline $\begin{array}{c}\text { Frequency, } \\
\mathrm{Hz}\end{array}$ & $\begin{array}{c}\text { Calculation (2D), } \\
\mathrm{W}\end{array}$ & $\begin{array}{c}\text { Experiment, } \\
\mathrm{W}\end{array}$ & $\begin{array}{c}\text { Discrepancy, } \\
\%\end{array}$ \\
\hline 50 & 1.692 & 1.893 & 11.9 \\
\hline 495 & 13.16 & 17.25 & 31.1 \\
\hline
\end{tabular}

Conclusion.

1. Our studies allow for taking into account the effects of eddy currents in a magnetic circuit by bringing its laminated parts to a homogeneous medium with the calculated values of the specific electrical resistance, so that it ensures the loss of power due to the effect of eddy currents in the real laminated axis and in the design twodimensional modeling plane.

2. Analysis of the saturation influence of the laminated magnetic circuit and its shape on the spatial distribution of his current density vector allow to establish an empirical relationship between the equivalent and actual specific electrical resistance of the material, size and shape of the sample.

3. Using the obtained equivalent resistance value for description the materials properties of objects with laminated magnetic circuits makes it possible to take into account the effects of eddy currents and corresponding power losses, in the two-dimensional approximation of the magnetic field, both in transitions and in steady-state mode.

\section{REFERENCES}

1. Gyselinck J., Vandevelde L., Melkebeek J., Dular P., Henrotte F., Legros W. Calculation of eddy currents and associated losses in electrical steel laminations. IEEE Transactions on Magnetics, 1999, vol.35, no.3, pp. 1191-1194. doi: $10.1109 / 20.767162$.

2. Gyselinck J., Sabariego R.V., Dular P. A nonlinear timedomain homogenization technique for laminated iron cores in three-dimensional finite-element models. IEEE Transactions on Magnetics, 2006, vol.42, no.4, pp. 763-766. doi: 10.1109/TMAG.2006.872034.

3. Kaimori H., Kameari A., Fujiwara K. FEM computation of magnetic field and iron loss in laminated iron core using homogenization method. IEEE Transactions on Magnetics, 2007, vol.43, no.4, pp. 1405-1408. doi: 10.1109/TMAG.2007.892429.

4. Zheng W., Cheng Z. An Inner-Constrained Separation Technique for 3-D Finite-Element Modeling of Grain-Oriented Silicon Steel Laminations. IEEE Transactions on Magnetics, 2012, vol.48, no.8, pp. 2277-2283. doi: 10.1109/TMAG.2012.2191591.

5. Pippuri J., Belahcen A., Dlala E., Arkkio A. Inclusion of eddy currents in laminations in two-dimensional finite element analysis. IEEE Transactions on Magnetics, 2010, vol.6, no.8, pp. 2915-2918. doi: 10.1109/TMAG.2010.2044490.

6. Dlala E., Belahcen A., Pippuri J., Arkkio A. Interdependence of hysteresis and eddy-current losses in laminated magnetic cores of electrical machines. IEEE Transactions on Magnetics, 2010, vol.46, no.2, pp. 306-309. doi: 10.1109/TMAG.2009.2032930.

7. Niyonzima I., Sabariego R.V., Dular P., Geuzaine C. Finite Element Computational Homogenization of Nonlinear Multiscale Materials in Magnetostatics. IEEE Transactions on Magnetics, 2012, vol.48, no.2, pp. 587-590. doi: 10.1109/TMAG.2011.2174210.

8. Koch S., Gersem H., Weiland T., Fischer E., Moritz G. Transient 3D Finite Element Simulations of the SIS100 Magnet Considering Anisotropic, Nonlinear Material Models for the Ferromagnetic Yoke. IEEE Transactions on Applied Superconductivity, 2008, vol.18, no.2, pp. 1601-1604. doi: 10.1109/TASC.2008.921892.

9. Ionel D.M., Popescu M., McGilp M.I., Miller T.J.E., Dellinger S.J., Heideman R.J. Computation of core losses in electrical machines using improved models for laminated steel. IEEE Transactions on Industry Applications, 2007, vol.43, no.6, pp. 1554-1564. doi: 10.1109/TIA.2007.908159.

10. Wei Chen, Jien Ma, Xiaoyan Huang, Youtong Fang. Predicting Iron Losses in Laminated Steel with Given NonSinusoidal Waveforms of Flux Density. Energies, 2015, vol.8, no.12, pp. 13726-13740. doi: 10.3390/en81212384.

11. Hollaus K., Hannukainen A., Schöberl J. Two-scale homogenization of the nonlinear eddy current problem with FEM. IEEE Transactions on Magnetics, 2014, vol.50, no.2, pp. 413-416. doi: 10.1109/TMAG.2013.2282334.

Received 02.07.2018

\author{
Makarchuk Oleksandr ${ }^{1,2}$, Doctor of Technical Science, \\ Associate Professor, \\ Calus Dariush ${ }^{1}, P h D$, Associate Professor, \\ Moroz Vlodimir ${ }^{1,2}$, Doctor of Technical Science, Professor, \\ Gatuszkiewicz Zbignew ${ }^{1}$, Mgr. Inż., \\ Gatuszkiewicz Patryk ${ }^{1}$, Mgr. Inż. \\ ${ }^{1}$ Czestochowa University of Technology, \\ Faculty of Electrical Engineering, \\ Institute of Electrical Power Engineering, \\ 17, Armii Krajowej Avenue, p.o. box 42-200 Częstochowa, \\ Poland, \\ e-mail: o.makarchuk@el.pcz.czest.pl; dc@el.pcz.czest.pl \\ ${ }^{2}$ Lviv Polytechnic National University, \\ Institute of Power Engineering and Control Systems, \\ 12, S. Bandera Str., Lviv, 79013, Ukraine, \\ phone +380 972259180 , \\ e-mail: oleksandr.v.makarchuk@lpnu.ua
}

How to cite this article:

Makarchuk O., Całus D., Moroz V., Gałuszkiewicz Z., Gałuszkiewicz P. Two-dimensional FEM-analysis of eddy currents loss in laminated magnetic circuits. Electrical engineering \& electromechanics, 2019, no.1, pp. 41-45. doi: 10.20998/2074-272X.2019.1.07. 